\title{
Personality profiles of recreational scuba divers
}

\author{
N. COETZEE \\ Department of Psychology, University of Pretoria, Pretoria, 0002, South Africa; E-mail: \\ nicoleen.coetzee@up.ac.za
}

(Sumitted: 19 July 2010; Revision accepted: 8 September 2010)

\begin{abstract}
Although classified as an extreme sport, recreational scuba diving differs substantially from other forms of extreme sport. As a result, several researchers have theorized that scuba divers would display unique personality traits but little research has thus far been conducted regarding the issue. Previous investigations tended to group participants of different types of extreme sports together before conducting personality studies. The aim of the present study was to explore which personality traits are prevalent amongst recreational scuba divers. In order to control for extraneous variables such as the level of proficiency in scuba diving and the interrelation between individuals and their natural environment, it was decided to include entry-level divers from the same geographical area in the sample. Sixty divers participated in the study. A personality questionnaire, the Clinical Analysis Questionnaire Part I, was administered. Sten scores were used as units of analysis. Frequency tables revealed high scores on self-sufficiency, boldness and impulsivity and low scores on conformity, warmth and sensitivity. The findings indicated that divers' personality traits differ from what the literature indicated to be typical of the extreme athlete's personality profile. An exploratory factor analysis was performed and four personality types, namely the adventurer, the rationalist, the dreamer and the passive-aggressive macho diver were identified. The results suggested that the amount of high-risk behaviour displayed by the diver would be dependent upon his/her personality type.
\end{abstract}

Key words: Extreme sport, recreational scuba diving, entry-level recreational scuba divers, personality traits, personality profiles.

\section{Introduction}

Recreational scuba diving is perceived to be an extreme sport since it involves physical and psychological risks (Farley, 1985; Slanger \& Rudestam, 1997; Jack \& Ronan, 1998; Zuckerman, 1983; 1985; 1994; 2000). Recreational scuba diving can be defined as diving for pleasure to depths of 18 meters without making decompression stops when returning to the surface (Charlston, 2007). This type of diving differs from technical diving since recreational scuba divers ascent directly to the surface while decompression stops are mandatory for technical divers (Charlston, 2007). Divers exploring caves or entering shipwrecks also exceed the limits set for recreational scuba divers and are thus busy with technical diving (Charlston, 2007).

Due to the uniqueness of the sport, several researchers have theorized that scuba divers would display specific personality traits (Morgan, 1983; Edmonds, 
McKenzie \& Thomas, 1997; Nevo \& Breitstein, 1999; Campbell, 2001) but little research has thus far been conducted regarding the matter. Most studies focused on determining the personality traits of navy divers (Biersner \& Cameron, 1970; Deppe, 1971; Biersner \& LaRocco, 1983). These studies have indicated that navy divers tend to be non-conformists, despite the military settings they operate in (Biersner \& Cameron, 1970); (Biersner \& LaRocco, 1983). Whether the same is true for recreational scuba divers, still remains to be seen.

With regard to South African research, Van Wijk (2002) deviated from the international trend of researching the personality traits of navy divers and conducted a study to determine the extent to which navy divers differed from recreational scuba divers. He administered the 16 Personality Factor Questionnaire on 28 South African Navy divers, 28 South African Navy nondivers and 28 civilian divers. Van Wijk's (2002) findings suggested that navy divers scored higher than navy non-divers and civilian divers on ego strength and were more tough minded and adventurous. He also found that navy divers were less assertive, obtained higher superego scores, were more practical and had a higher self-sentiment. Although Van Wijk's study gave some indication of the personality traits prevalent amongst various types of divers, its main focus was to determine how non-navy and civilian divers differed from navy divers and no attempt was made to determine whether the non-navy and civilian divers differed with regards to personality profiles from one another.

Echoing the sentiments of those studying scuba diving (Morgan, 1983; Edmonds et al., 1997; Nevo \& Breitstein, 1999; Campbell, 2001), researchers in sport psychology noted that certain personality types are attracted to a particular sport (Schurr, Ashley \& Joy, 1977; Weinberg \& Gould, 2007). Subsequent to these findings, studies emerged which investigated the personality of individuals involved in extreme sport. The problem with these studies, however, is that diverse groups of extreme athletes (for example scuba divers, sky-divers, mountaineers, hang gliders, etc.) were grouped together to form a high risk group that was then studied (Freixanet, 1999), or that was compared to athletes not participating in high-risk events (for example swimmers, golfers, marathon runners, etcetera) (Slanger \& Rudestam, 1997; Jack \& Ronan, 1998; Murray, 2003). Freixanet (1999) as well as Slanger and Rudestam (1997) learned that extreme athletes are extroverts that will, despite their sensation-seeking nature, conform to social norms. It is still uncertain to what extent these results could be generalized to recreational scuba divers in particular. Recreational scuba diving and sky diving, for example, differ with regard to equipment as well as physiological risks involved. Recreational scuba divers must know how to operate safely while submerged 18 meters under water while sky-divers must know what to do whilst free falling from an aircraft to the earth below at several meters per second. 
In order to learn more about the personality traits and types of recreational scuba divers, research is needed where the focus will be on individuals participating in recreational scuba diving. It is thus the aim of this study to determine which personality traits are prevalent amongst recreational scuba divers. Additionally, factor analysis was used to identify the personality types of those individuals drawn to the sport of recreational scuba diving.

\section{Materials and Methods}

Only entry-level (beginner) recreational scuba divers from the same geographical area participated in the study, as the amount of years participating in the sport as well as environmental inconsistencies could be extraneous variables (Roberts \& Wood, 2006). Ten scuba diving schools within Gauteng were randomly selected from the South African Divers Alert Network website (www.dan-sa.org) to be included in the study but only six agreed to participate. Newly enrolled entrylevel divers were identified and asked to volunteer to participate in the study and sixty (60) divers (30 males; 30 females) volunteered to serve as participants. Participating divers were aged from 16 to 35 years $(M=27.6, S D=4.74)$. Each participant signed a consent form to confirm their voluntary participation in the study and to indicate that the results may be used for research purposes.

Instrument of the Study

Clinical Analysis Questionnaire (CAQ).

The CAQ is a pencil-and-paper personality questionnaire which has 272 items. Part I of the questionnaire consists of 128 items pertaining to personality traits while Part II comprises the remaining 144 questions (Zaza \& Barké, 1986; Krug, Cattell \& IPAT Staff, 1997). The latter involves the measurement of pathology which was deemed not important for the present study and hence participants were not required to complete it. Research conducted on the CAQ yielded reliability coefficients of up to 0.80 (Zaza \& Barké, 1986) and validity coefficients of up to 0.78 (Krug et al., 1997). Sten scores were used as units of analysis. In addition, an exploratory factor analysis was used to see to determine the extent to which these traits correlate with one another and group together to form the personality types of those individuals drawn to the sport of recreational scuba diving.

\section{Administration of the Instrument}

Each scuba diving school was visited, according to prior arrangement with the scuba instructor, by the researcher on the first day of the entry-level divers' scuba diving training. All scuba diving schools had small lecture-like venues where the Researcher personally administered Part I of the CAQ to participants. 
The CAQ data were collected within one month. It took between 20 to 30 minutes to complete Part I of the questionnaire.

Data Analysis

The collected data yielded raw scores for each participant on 16 personality traits. These raw scores were converted with the aid of norms included in the CAQ manual (Krug et al., 1997) into sten scores that were used as units of analysis in the study. In order to determine how these sten scores were distributed amongst the 16 personality traits, measures of central tendency and variation were computed for each of the traits. In order to measure the most prevalent personality traits, frequency distributions were constructed for each personality trait. According to the Manual of the CAQ (Krug et al., 1997), a sten equal to four or lower is perceived as a low score while anything from seven and higher are perceived as high scores. Next, an exploratory factor analysis was performed on the data. Normally, factor analysis has specific constraints with regards to sample size. It was however determined that if distinct factors are known to be present (Pallant, 2007; Tabachnick \& Fidell, 2010) and the analysis

is conducted solely to simplify data in a scientific manner to explore for systematic tendencies (Madge, 1973), such constraints could be relaxed. Since a confirmatory factor analysis by the developers of the CAQ confirmed the existence of clear and distinct factors in the form of 16 personality traits (Krug et al., 1997), and the main aim of further analysis was to combine personality traits into smaller elements or factors (Thurstone, 1959) in order to provide an idealized description of the personality types of entry-level recreational scuba divers (Cudeck, 2007), an exploratory factor analysis was deemed appropriate.

Due to the exploratory nature of the factor analysis, a decision was made to use a Scree Plot to determine the number of factors for extraction. The use of a scree plot prevents the intrusion of non-common variance (Thompson, 2004). Guided by the scree plot, four factors were extracted for analytical purposes. A Varimax rotation was performed in order to obtain the final factor matrix.

\section{Results and Discussion}

In order to measure central tendency, mean scores were computed for the standardized scores of each of the 16 personality traits. Variability was measured by calculating the standard deviations for these scores. The results obtained are indicated in Table 1. 
As can be seen in Table 1, sten averages varied between 4.52 and 6.10. Standard deviations were low and ranged from 1.42 to 2.04. As was mentioned previously, frequency distributions were constructed for each personality trait. By setting up distributions where standardized scores were placed from low to high on each of the 16 personality traits, a clear picture emerged of the personality traits most prevalent amongst the participants. A summary of the results related to the frequency distributions are depicted in Table 2.

Table 1: Means and standard deviations for the personality traits of divers based on the CAQ

\begin{tabular}{llll}
\hline Personality trait & $N$ & $M$ & $S D$ \\
\hline A: Warmth & 60 & 4.71 & 1.75 \\
B: Intelligence & 60 & 4.52 & 1.81 \\
C: Emotional stability & 60 & 4.64 & 1.93 \\
E: Dominance & 60 & 5.71 & 1.68 \\
F: Impulsivity & 60 & 5.59 & 2.04 \\
G: Conformity & 60 & 4.85 & 1.64 \\
H: Boldness & 60 & 6.00 & 1.88 \\
I: Sensitivity & 60 & 5.20 & 1.99 \\
L: Suspiciousness & 60 & 6.10 & 1.42 \\
M: Imagination & 60 & 5.14 & 1.58 \\
N: Shrewdness & 60 & 5.24 & 1.70 \\
O: Insecurity & 60 & 5.68 & 1.66 \\
Q1: Radicalism & 60 & 5.34 & 1.63 \\
Q2: Self-sufficiency & 60 & 5.88 & 1.90 \\
Q3: Self-discipline & 60 & 5.42 & 1.64 \\
Q4: Tension & 60 & 5.78 & 1.80 \\
\hline
\end{tabular}

Table 2 indicates that a significant amount of the participants obtained high scores on boldness, suspiciousness, self-sufficiency and tension. Low scores were obtained on warmth, emotional stability, conformity, sensitivity and imagination.

Earlier it was stated that an exploratory factor analysis with a varimax rotation was performed in addition to the descriptive statistics. The results for this analysis are presented in Table 3. 
Table 2: A summary of the frequency distributions for the 16 personality traits of the CAQ

\begin{tabular}{|c|c|c|c|}
\hline Factor & $1-4$ & $5-6$ & $7-10$ \\
\hline A: Warmth & $26(43.3)$ & $26(43.3)$ & $7(11.7)$ \\
\hline B: Intelligence & $31(51.7)$ & $21(35)$ & $6(10)$ \\
\hline C: Emotional stability & 26(43.3) & $24(40)$ & $9(15)$ \\
\hline E: Dominance & $12(20)$ & $30(50)$ & $17(28.3)$ \\
\hline F: Impulsivity & $14(23.3)$ & $28(46.7)$ & $17(28.3)$ \\
\hline G: Conformity & $24(40)$ & $25(41.7)$ & $10(16.7)$ \\
\hline H: Boldness & $14(23.3)$ & 23(38.3) & 22(36.7) \\
\hline I: Sensitivity & 27(45) & $16(26.7)$ & $16(26.7)$ \\
\hline L: Suspiciousness & $8(13.3)$ & $26(43.3)$ & 25(41.7) \\
\hline M: Imagination & $24(40)$ & 23(38.3) & $12(20)$ \\
\hline N: Shrewdness & $14(23.3)$ & $37(61.7)$ & $8(13.3)$ \\
\hline O: Insecurity & $16(26.7)$ & $24(40)$ & 19(31.7) \\
\hline Q1: Radicalism & $18(30)$ & $27(45)$ & $14(23.3)$ \\
\hline Q2: Self-sufficiency & $15(25)$ & $17(28.3)$ & 27(45) \\
\hline Q3: Self-discipline & $15(25)$ & $31(51.7)$ & $13(21.7)$ \\
\hline Q4: Tension & $12(20)$ & $26(43.3)$ & 21(35) \\
\hline
\end{tabular}

As was seen in Table 3, Factor 1 had the highest number of loadings when compared to the other three factors. Seven of the personality traits measured in Part I of the CAQ displayed high loadings on Factor 1. These factor loadings imply that this group of divers' personality can be described as bold, dominant, emotionally stable, impulsive, secure, relaxed and forthright (Krug et al., 1997).

Based on this it was decided to label this type of entry-level recreational scuba diver "the adventurer". Four CAQ traits, on the other hand, grouped together to form Factor 2. In accordance with the descriptions provided by the CAQ manual, it was decided to label this personality profile "the rationalist". Factor 3 consisted only of two traits that loaded positively high onto it. Based on the description that Krug et al. (1997) assigned to the traits contained in this factor, it was decided to name this particular personality profile "the dreamer". The last factor was labelled the "passive-aggressive macho person" because Suspiciousness and Warmth loaded positively onto it whilst Self-sufficiency displayed a negative loading. These four factors explained $52.9 \%$ of the variance in the data set. 
Table 3: Factor matrix obtained for four (4) factors (Varimax rotation)

\begin{tabular}{lllll}
\hline CAQ Personality Trait & Factor 1 & Factor 2 & Factor 3 & Factor 4 \\
\hline H : Boldness & 0.78 & & & \\
E : Dominance & 0.72 & & & \\
C : Emotional stability & 0.69 & & 0.41 \\
F : Impulsivity & 0.60 & & 0.31 \\
N : Shrewdness & -0.33 & & & \\
Q4 : Tension & -0.56 & -0.37 & & \\
O : Insecurity & -0.67 & & & \\
Q3 : Self-discipline & & 0.64 & & \\
B : Intelligence & & 0.61 & & \\
G : Conformity & & 0.53 & & \\
Q1 : Radicalism & & -0.61 & 0.35 & \\
I : Sensitivity & & & 0.82 & \\
M : Imagination & & & 0.80 & \\
L : Suspiciousness & & & & 0.58 \\
A : Warmth & & & & \\
Q2 : Self-sufficiency & & & & \\
\hline
\end{tabular}

A significant amount of the participants obtained high scores (sten 7-10) on boldness (Table 2). Boldness as a personality trait is indicative of adventurous and energetic individuals (Krug et al., 1997). Since recreational scuba diving could be described as a physically demanding sensation seeking activity (Zuckerman, 1994; 2000; Murray, 2003; Charlston, 2007), it would only be natural for those who are interested to participate in it, to be highly active individuals looking for adventure. The low scores (sten 1-4) displayed on imagination indicate that the participants are individuals who have the ability to deal with mechanical things and pay particular attention to detail. These traits are necessary for the diver because to be successful in scuba diving, individuals must display intimate knowledge of the industrial equipment they rely on for their physical safety when submerged underwater (Coetzee, 2005). Concern with regard to the low scores on emotional stability and high scores on tension were explained by Krug et al. (1997) in the CAQ manual. Accordingly, low scores on emotional stability and high scores on tension are actually indicative of an 
underlying anxiety pattern. Keeping in mind that the participants under investigation were new to the sport, it is concluded that they experienced anxiety because they did not know what awaited them.

The high scores (sten 1-10) on self-sufficiency and suspiciousness also make more sense when it is interpreted in relation to the low scores (sten 1-4) on warmth, conformity and sensitivity. These scores combined suggest that the participants of the study are non-conforming, self-reliant individuals who prefer to do things on their own and do not value group membership as important (Krug et al., 1997; Coetzee, 2005). Although research has indicated that navy divers' personality traits differ from those of non-navy and civilian divers (Van Wijk, 2002), the last-mentioned findings suggest that these groups have more in common than was initially suspected (Biersner \& Cameron, 1970; Biersner \& LaRocco, 1983). It thus seems that entry-level recreational scuba divers are similar to navy divers and would display a need for autonomy whilst avoid seeking grouping membership or approval. These findings, as was expected, contradict those of Freixanet (1999) and Slanger and Rudestam (1997) who concluded that extreme athletes are mostly extroverts who tend to conform to social norms. It also confirms the notion that scuba divers have unique personality traits and thus could not be equated to other extreme athletes when research on personality is conducted. The exploratory factor analysis identified four profiles, namely the Adventurer, the Rationalist, the Dreamer and the Passive-Aggressive Macho Diver. Each of these profiles will be discussed next.

Adventurers:

Adventurers are very focused and enthusiastic individuals. They approach all their activities in an attentive and lively way. Although these divers appear easy to get along with, their competitive edge and their urge to be the focus of attention could lead to the taking of unnecessary risks that might endanger not only their lives, but the lives of their diving partners as well (Krug et al., 1997; Coetzee, 2005).

\section{Rationalist:}

This particular type of diver may be described as an intelligent individual who has strong control over his/her emotional life and behaviour in general. Unlike most other recreational scuba divers, they will display conforming behaviour if the context demands it. They will also be respectful and mindful of scuba diving rules and regulations. Entry-level recreational scuba divers who demonstrate this specific personality type will persist until they master the required scuba skills 
and will attentively follow the instructions of those in authoritative positions, such as the instructor or the dive master. Rationalists are rule-bound individuals that will not take any unnecessary risks while underwater (Krug et al., 1997; Coetzee, 2005).

The dreamer:

This personality profile is representative of those divers who are unconcerned about everyday matters and appear to be absent-minded (Krug et al., 1997). They choose to participate in recreational scuba diving because they believe it will help them escape from their mundane lives and open up a whole new world for them (Coetzee, 2005). However, once they realize that the sport is quite challenging and demanding, they might be at risk of becoming overly dependent on the diving instructor, their diving partners or both. As a result, they would repeatedly seek confirmation from instructors and/or diving partners that they are doing something right. This might result in other divers and instructors wrongfully assuming that the dreamer has not been paying attention and they could display signs of irritation. They would thus not realize that the dreamer is actually insecure and feels overwhelmed by the scuba diving context (Krug et al., 1997; Coetzee, 2005).

The Passive-Aggressive Macho Diver:

At first glance, it does not seem as if there are any connections between the personality traits that grouped together to form this profile. However, a study of the descriptions of the traits underlying this personality will reveal that passiveaggressive macho divers will, when they are introduced to others, appears to be warm-hearted, pleasant and charming individuals (Krug et al., 1997). Yet, once they gain group membership, they will start to display antisocial behaviour by constantly criticizing other divers' performance, being irritable with divers who struggle and express the belief that their performance as divers is superior and that everybody (instructors included) could learn from them (Krug et al., 1997; Coetzee, 2005). This is not the first study to learn about such a personality profile amongst scuba divers as other reports are available (Bachrach \& Egstrom, 1987; Scuba Schools International, 1990). Bachrach and Egstrom (1987) were convinced that these divers use passive-aggressive behaviour as a defence mechanism in order to hide the fact that they were actually anxious and nervous when participating in recreational scuba diving. They are thus individuals who lack self-confidence and have low self-esteem. In order for them to feel good 
about themselves, they experience a constant need to compare themselves with others, making themselves believe that they are better and more worthy (Coetzee, 2005).

\section{Conclusions and recommendations}

The present findings indicated that scuba divers' personality traits differ from those of other extreme athletes and thus research findings from the latter could not be generalized to the diving context. The four different personality types confirm several researchers' hypothesis that various personality types exist within the recreational scuba diving environment (Morgan, 1983; Edmonds et al., 1997; Nevo \& Breitstein, 1999; Campbell, 2001). It further proves that it is statistically possible to distinguish amongst individuals who participate in recreational scuba diving. The personality traits identified to be most prevalent amongst entry-level recreational scuba divers were not equally distributed amongst the factor structure of the four personality types. It is therefore assumed that, although entry-level recreational scuba divers could be described as bold, adventurous, self-sufficient and non-conforming sensation seekers, the amount of risk they are willing to take would be dependent upon their personality. Their personality type would also determine to what extent would they adhere to scuba diving rules and regulations and would be willing to dive within the confounding boundaries of a group or the "buddy-system”.

Another possible explanation for the unequal distribution of the identified personality traits amongst the factor structure of the four personality types might relate to the size of the sample. The present findings must thus be interpreted with some caution. It is recommended that future studies should attempt to use bigger samples. It is further recommended that more research is necessary, not only to validate the existence of the personality traits and types identified within the context of the present study, but also to identify those personality traits and types that did not come to the fore during the present investigation.

\section{References}

Bachrach, A.J. \& Egstrom, G.H. (1987). Stress and Performance in Diving. San Pedro, California: Best Publishing Co.

Biersner, R.J. \& Cameron, B.J. (1970). Betting preferences and personality characteristics of navy divers. Aerospace Medicine, 44, 1289-1291.

Biersner, R.J. \& LaRocco, J.M. (1983). Personality characteristics of US Navy divers. Journal of Occupational Psychology, 56, 329-334. 
Campbell, E. (2001). Psychological issues in diving. Retrieved October, 16, 2001 from http://www.diversalertnetwork.org/medical/articles/article.asp?articleid=31.

Charlston, J.A. (2007). Scuba diving. Berkshire Encyclopedia of Extreme Sports, 267-270.

Coetzee, N. (2005). Behavioural correlates, stress, anxiety and panic in recreational scuba divers: A psychophysiological perspective. Unpublished doctoral dissertation, University of Limpopo, Medunsa Campus, South Africa.

Cudeck, R. (2007). Factor analysis in the year 2004: Still spry at 100. In R. Cudeck \& R.C. MacCallum (Eds.). Factor Analysis at 100. Mahwah, New Jersey: Lawrence Erlbaum Associates, Publishers.

Deppe, A.H. (1971). A study of psychological factors relevant to the selection of scuba divers. Published doctoral dissertation, UNISA, South Africa.

Edmonds, C., McKenzie, B. \& Thomas, R. (1997). Diving Medicine for Scuba Divers (2 ${ }^{\text {nd }}$ ed.). Melbourne: J.L. Publications.

Farley, F. (1985). Psychobiology and cognition: An individual differences model. In J. Strealau, F.H. Farley \& A. Gale (Eds.). The Biological Bases of Personality and Behavior: Theories, Measurement Techniques and Development. Washington: Hemisphere Publishing.

Freixanet, M.G.I. (1999). Personality profiles of subjects engaged in high physical risk sports. Human Performance in Extreme Environments, 4 (2), 11-17.

Jack, S.J. \& Ronan, K.R. (1998). Sensation seeking among high- and low-risk sports participants. Personality and Individual Differences, 25, 1063-1083.

Krug, S.E., Cattell, R.B. \& IPAT Staff. (1997). Clinical Analysis Questionnaire Manual. Champaign, Illinois: Institute for Personality and Ability Testing, Inc.

Madge, E.M. (1973). Inleiding tot Faktorontleding. Pretoria: HSRC

Morgan, W.P. (1983). Psychological problems associated with the wearing of industrial respirators: A review. American Industrial Hygiene Association Journal, 44 (9), 671-676.

Murray, D.M. (2003). Living on the edge: Sensation seeking and extreme sports participation. Unpublished dissertation, University of Connecticut, United States of America.

Nevo, B. \& Breitstein, S. (1999). Psychological and Behavioral Aspects of Diving. Arizona, USA: Best Publishing Company.

Pallant, J. (2007). SPSS Survival Manual ( $3^{\text {rd }}$ ed.). Berkshire, England: McGraw Hill Open University Press.

Palmeri, C. (1996). Go Scuba!. Forbes, 157 (5), 132-134.

Roberts, B.W. \& Wood, D. (2006). Personality development in the context of the NeoSocioanalytic Model of personality. In D.K. Mroczek \& T.D. Little (Eds.), Handbook of Personality Development (pp. 11-19). New Jersey: Lawrence Erlbaum Publishers.

Scuba Schools International (1990). Diver Stress \& Rescue. Fort Collins: Concept Systems. 
Schurr, K.T., Ashley, M.A. \& Joy, K.L. (1977). A multivariate analysis of male athlete characteristics: Sport type and success. Multivariate Experimental Clinical Research, 3, 53-68.

Slanger, E. \& Rudestam, K.E. (1997). Motivation and disinhibition in high risk sports: Sensation seeking and self-efficacy. Journal of Research in Personality, 31, 355-374.

Tabachnick, B.G. \& Fidell, L.S. (2001). Using Multivariate Statistics ( $4^{\text {th }}$ ed.). Boston: Allyn and Bacon.

Thompson, B. (2004). Exploratory and Confirmatory Factor Analysis: Understanding Concepts and Applications. Washington, D.C.: American Psychological Association.

Thurstone, L.L. (1959). Multiple Factor Analysis. Chicago: University of Chicago Press.

Van Wijk, C. (2002). Comparing personality traits of navy divers, navy-non divers and civilian sport divers. South Pacific Underwater Medicine Society (SPUMS) Journal, 32 (1), 2-8.

Weinberg, R.S. \& Gould, D. (2007). Foundations of Sport and Exercise Psychology (4 $4^{\text {th }}$ ed.). Illinois: Human Kinetics.

Zaza, A.S. \& Barké, C.R. (1986). A review of the Clinical Analysis Questionnaire. Journal of Counseling and Development, 64, 413-414.

Zuckerman, M. (1983). Sensation seeking and sports. Personality and Individual Differences, 4, 285-293.

Zuckerman, M. (1994). Behavioral Expressions and Biosocial Bases of Sensation Seeking. New York: Cambridge University Press.

Zuckerman, M. (2000). Are you a risk taker? Psychology Today, 33 (6), 52-87. 